\title{
CONVENCIONES DEL GÉNERO DE CAPA Y ESPADA EN LA DÉCADA DE 1630: EL DOCTOR CARLINO, DE ANTONIO DE SOLÍS ${ }^{1}$
}

\author{
Judith Farré \\ Consejo Superior de Investigaciones Científicas \\ Centro de Ciencias Humanas y Sociales \\ Instituto de Lengua, Literatura y Antropología \\ c/ Albasanz 26-28 \\ 28037 Madrid \\ judith.farre@cchs.csic.es
}

[Anuario calderoniano (ISSN: 1888-8046), 6, 2013, pp. 95-109]

Son abundantes en el siglo XVII comentarios como los de Suárez de Figueroa en El pasajero, en los que ironiza sobre la práctica siste-

${ }^{1}$ Este trabajo se inscribe en el marco del programa Ramón y Cajal (RYC-200802362) y del proyecto «Edición y estudio del teatro breve de Antonio de Solís», del Plan Nacional de I+D+i (FFI2011-25118). Cuenta con el patrocinio de TC-12, en el marco del Programa Consolider-Ingenio 2010, del Plan Nacional de Investigación Científica, Desarrollo e Innovación Tecnológica (SD2009-00033). 
mática de los mecanismos de enredo básicos de la comedia nueva ${ }^{2}$, y que ya en la época apuntan a que «existía la conciencia de un tipo de comedia especial, con tema amoroso y ambiente coetáneo y urbano, con personajes particulares y basada fundamentalmente en el ingenio", como ha puesto de relieve Arellano a la hora de trazar las convenciones del género ${ }^{3}$. A partir de esta conciencia adquirida, la evolución del género puede trazarse considerando una serie de recursos que se orientan hacia la manifestación y estilización del ingenio y que, en todos los casos, apuntan hacia una clara ruptura de la verosimilitud dramática. Se produce así una mecanización de los recursos que supone una convencionalización extrema de la comedia de capa y espada, cuyo efecto inmediato es, de nuevo en palabras de Arellano, una «inverosimilitud ingeniosa y sorprendente, capaz de provocar la admiración y suspensión del auditorio» ${ }^{4}$.

A mediados del siglo XVII, los dramaturgos continuaban bien conscientes de los recursos del género y, si bien no existía una reflexión teórica sistematizada en torno a los mecanismos del enredo que pautara un molde genérico previo -El hombre práctico del conde de Fernán Núñez se publicó en 1686 y Bances Candamo redactó su Teatro de de los teatros entre 1689 y $1694^{5}$ - cabe decir que existía de hecho. Ya sucedió también así a principios del siglo XVII, con el teatro de Lope de Vega, que fue el que realmente marcó tendencia, por encima de la propuesta teórica de su Arte nuevo (1609). En la misma dirección apuntaban las demandas del público, que se había convertido, además, en un auditorio experimentado que veía el teatro y en algunos casos también leía las comedias y sus relaciones. Todo el entramado imponía una continua revisión de todos estos mecanismos por parte de los dramaturgos, que sólo así podrían sorprender a un público anheloso de novedades. En este sentido, las continuas alusiones literarias que pueden rastrearse en las comedias desde mediados del siglo XVII pueden leerse como un signo explícito del horizonte de expectativas sobre el que se proyectan. Desde esta óptica, Maria Grazia

2 Tomo el ejemplo de Julio, 1997, pp. 237-238.

3 Arellano, 1988, p. 29.

${ }^{4}$ Arellano, 1988, p. 32.

${ }^{5}$ Para una reflexión de conjunto sobre la poética del momento, resulta muy esclarecedor el trabajo de Checa (2012), que incide en este y otros puntos de manera muy ilustrativa. 
Profeti ya lo estudió al establecer la década de 1630 como el momento en que la comedia de enredo se vuelve cada vez más ingeniosa, «llegando a dominar una actitud y una mirada meta-textual que parodia los mismos tópicos en que la comedia se funda» ${ }^{6}$. Uno de los ejemplos paradigmáticos de esta tendencia es Calderón y quizá El escondido y la tapada pueda representar, como ya pusiera de manifiesto Jesús Sepúlveda (2003), el haz y el envés de las convenciones del género ${ }^{7}$. Análogamente, la crítica ha señalado cómo otras comedias del corpus calderoniano se encaminan hacia esta misma dirección de aprovechamiento de las estrategias dramáticas propias de la morfología del género y pueden verse como una búsqueda intencionada de nuevos efectos al llevar al extremo las posibilidades combinatorias de la comedia de capa y espada. Pero esa búsqueda no es exclusiva de Calderón y puede hacerse extensible a otros dramaturgos coetáneos.

Otro de los aspectos clave a considerar en la peculiar evolución de la comedia de capa y espada es la tendencia a la generalización del agente cómico, como ya estudiara Arellano (Arellano, 1994). Así, el ambiente cómico generalizado de las primeras comedias urbanas de Lope, en las que está todavía muy presente «el peso de la concepción clásica de la comedia como reino de lo bajo-risible, frente al mundo de la tragedia» ${ }^{8}$, tiene matices distintos a la extensión de los agentes cómicos que se observa en la segunda mitad del siglo XVII, más cercanos al entremés, la comedia de figurón y la burlesca.

Calderón es, necesariamente, quien mejor partido saca de la necesidad de llevar hasta el extremo los mecanismos de enredo del género de boga en los escenarios del momento, la comedia de capa y espada, pero, como apuntábamos, no es el único y, en este sentido, Antonio de Solís se nos presenta como un dramaturgo de oficio, que es capaz de explotar al máximo todas las posibilidades de la comedia de intriga. Inicia su labor dramática en 1627, con Amor y obligación, y ésta se extiende hasta 1658, con Triunfos de Amor y Fortuna. Su producción apenas alcanza las trece comedias — si contamos las reescri-

6 Profeti, 1997, p. 18.

${ }^{7}$ En este punto es necesario retomar las conclusiones de Agustín de la Granja en las que se pregunta si la comedia «en todo su conjunto no es respuesta y réplica a tanto pullazo del público contra el escritor y contra sus dos pasos preferidos de "tapadas" y “escondidos”" (Granja, 1997, p. 83).

${ }^{8}$ Arellano, 1994, p. 108. 
turas de La gitanilla de Madrid y Eurídice y Orfeo-, pero tiene el mérito de localizarse en los años en los que el género se somete a este proceso de mecanización y revisión de sus estrategias de enredo9

Gracias a la exhaustiva biografia que trazó Frédéric Serralta, sabemos que, en un periodo inicial de su actividad creadora, que va desde 1627 a 1636, Solís cursó estudios en Salamanca y, ya establecido en Madrid, publicó sus primeras comedias y fue contertulio habitual de las academias más concurridas de la capital. Entre 1636 y 1639 (probablemente en 1637) el dramaturgo entró al servicio del que sería su mecenas, el séptimo conde de Oropesa ${ }^{10}$, un cargo que le valió ser nombrado secretario de Felipe IV en $1651^{11}$ y que marcaría la segunda etapa creadora, centrada en sus piezas de encargo palaciegas, que duraría hasta 1660 , momento en el que fue nombrado cronista real de Indias y abandonaría su oficio teatral para centrarse exclusivamente en su Historia de la conquista de México. De hecho, Amor es arte de amar es la última comedia que el dramaturgo dejó inconclusa, apenas escribió hasta la mitad de la primera jornada, para pasar a dedicarse en exclusiva a su faceta de historiador.

$\mathrm{Su}$ designación como sucesor en el puesto que dejaba vacante Antonio León Pinelo no parece a todas luces muy justificada, ya que Solís nunca había tenido relación con las Indias ni contaba con ninguna experiencia personal americana, y, desde luego, no estaba familiarizado con las labores de historiador o de cronista. Su elección frente a don José Pellicer puede interpretarse como una «merced» que premiaba sus éxitos como dramaturgo, y así se desprende de unos comentarios que vertía Jerónimo de Mascareñas, un historiador portugués, cuando a raíz de una polémica por una censura emitida por Solís, escribía que: «Su inteligencia en las materias de la Historia es sumamente corta, y en ninguna manera es ascenso natural pasar de los chistes de las Comedias, que es su profesión, al puesto de Coronista de un tan gran Monarca» ${ }^{12}$.

${ }^{9}$ Un aspecto que ya puso de manifiesto Serralta en su monografia de 1987 al estudiar en profundidad cinco de sus comedias.

10 Serralta, 1986, pp. 65-66.

11 Serralta, 1986, p. 84.

12 Dato tomado de Cid, 1991, p. 91 . Solís terminó el encargo de escribir la Historia de México en 1682, tras un largo proceso de revisión de las fuentes (Cortés, Gómara, Bernal Díaz del Castillo, Herrera) y correcciones al manuscrito original, que puede 
Aunque Solís no llegó a alcanzar nunca el reconocimiento ni los méritos de Calderón, sí fue un dramaturgo apreciado por las élites y el público de su época y son muchas las relaciones que pueden establecerse entre ambos. De hecho, Serralta (1987) ya señaló las huellas temáticas de Calderón en una de las comedias cortesanas de Solís, Amparar al enemigo (1642), y el mismo crítico, en colaboración con Arellano, publicaba en un volumen de 1996 la única edición crítica de una comedia de Solís, El amor al uso, junto a la calderoniana Mañanas de abril y mayo, una sociedad que los editores justificaban no sólo por las relaciones temáticas entre las dos comedias, sino también por el valor intrínseco de la comedia de Solís "que no sólo no desdice de su ilustre fuente, sino que muy probablemente la supera en no pocos aspectos» ${ }^{13}$. Todavía resulta necesario establecer un compendio sistemático de influencias, préstamos y autoplagios entre los dramaturgos del momento, en aras de fijar una cronología que, considerando fechas de estreno y de impresión, permita observar la evolución que va siguiendo el género. Mi propósito en estas líneas es abordar las complicidades entre Calderón y Solís en torno a esta década de 1630 y, en este contexto de estrategias compartidas, analizar la comicidad ingeniosa que, según pautas calderonianas, exhibe Solís con el manejo de las convenciones genéricas en El doctor Carlino, de la que un contemporáneo comentaba

Hoy vive, y yo le conozco, un caballero de esa noble familia de Solís, llamado Don Antonio, persona más ilustre aún por su elevado ingenio, que es tenido en esta Corte por uno de los mayores, que ha escrito mu-

seguirse bien a través de su correspondencia y que ha sido ampliamente documentado por la crítica que, según unánime opinión, sostiene que Solís no añadió nada nuevo a los datos históricos ya publicados. Con todo, el mérito que se le reconoce radica en su hábil entretejido "de lo que encontró en sus fuentes, poniendo de su parte una excelente retórica adaptada a los lectores de su tiempo» (Cid, 1991, p. 92). Los elogios que recibe su Historia, al tiempo que recalcan su valor «a la hora de entretejer los sucesos» — tal y como expone Solís en su prólogo-, destacan su dimensión literaria, aspecto que, lógicamente, implica su descrédito como documento historiográfico, pero que pueden ser reveladores para trazar su perfil como dramaturgo a la hora de entretejer comedias. Véase también Arocena, 1963, pp. 259-275.

13 Calderón, Mañanas de abril y mayo, p. 9. 
chas comedias, y entre ellas una muy celebrada que no ha mucho se representó en esta, titulada El doctor Carlino ${ }^{14}$.

La extensa y documentada biografia del dramaturgo alcalaíno que trazó Serralta fechaba la comedia en un período de redacción entre 1651 y 1658. El investigador francés concluía que «objetivamente bien podría ser de 1635 pero que, según frágiles indicios me parece más propia de la segunda época de Solís» ${ }^{15}$, aunque creo que la redacción de la comedia debe situarse ya en torno a 1635 . La reciente publicación del Diccionario biográfico de autores teatrales (DICAT) pone de manifiesto que El doctor Carlino formaba parte del repertorio de la compañía de Prado en julio de $1635^{16}$. Debe tratarse, forzosamente, de la comedia de Solís, puesto que Góngora no llegó a acabar la suya y en esta década de 1630 Solís ya había escrito otras comedias con cierto éxito (La gitanilla de Madrid y El amor al uso).

Así pues, El doctor Carlino de Solís, comedia homónima de la de Góngora compuesta en $1613^{17}$, fue escrita en torno a 1635 , y se enmarca de lleno en la tendencia general de la comedia de capa y espada que, alrededor de la década de 1630, da una vuelta de tuerca más, volviéndose cada vez más ingeniosa y mostrando un «universo textual profundamente literaturizado» ${ }^{18}$. En esta dirección apunta el análisis de El escondido y la tapada, por parte de Jesús Sepúlveda, cuando al tratar sobre las esporádicas alusiones al mundo del teatro, afirma que

[se trata de] un resorte autorreferencial mediante el que no sólo se rompe la ilusión escénica, sino por el que se le recuerda al público el carác-

${ }^{14}$ Arocena, 1963, p. 63.

15 Serralta, 1986, p. 63.

16 Consta una escritura, fechada en Esquivias (Toledo) el 13 de julio de 1635, por la que Cebrián Martínez, miembro de la compañía de Prado y apoderado de dicho autor, se concertó para que la compañía acudiese a Esquivias el sábado de la Octava de la Asunción para representar, entre otras piezas breves, dos comedias. Las comedias serían elegidas por los comisarios de la fiesta y escogerían entre Casa con dos puertas, El doctor Carlino, La Sierralonga u otra cualquiera del repertorio de Prado.

${ }^{17} \mathrm{La}$ repercusión del modelo puede rastrearse en otras piezas, como el entremés que publicara Restori en 1903 [Restori, Piezas de títulos de comedias, Messina,Vicenzio Muglia, 1903, pp. 129-141]. Dato tomado de Dolfi, 1989, p. 483.

18 Sepúlveda, 2003, p. 817. 
ter convencional del subgénero, reclamando momentáneamente su atención sobre los hilos con que se compone el tapiz y no sobre la figura dibujada. Este abandono fugaz de la historia representada adquiere, a su vez, un innegable valor cómico y acaba constituyéndose como un elemento más del cliché ${ }^{19}$.

Así, bajo estos parámetros de género y en las mismas fechas que se observa en Calderón, esa tendencia es clara en la comedia de Solís y, de entrada, se observa en el título, que se refiere al de Góngora. Laura Dolfi alude al "diferente tejido del enredo» que distingue la comedia de Solís respecto a la de Góngora. Pues mientras en el Carlino gongorino todo se orienta hacia la burla y la boda final entre el doctor y Casilda ${ }^{20}$, en la comedia de Solís la trama se complica ya que son dos las parejas de amantes que cerrarán con boda final y, además, se enmaraña con distintos cambios de identidad y los consiguientes celos y equivocaciones. Así es, ya que el protagonismo de un falso doctor y alcahuete lo equipara a las dos parejas de nobles de la comedia, pues se apropia también, como ellos, de una identidad fingida. La peculiaridad de su caso es que se oculta bajo el personaje dramático ideado por Góngora y el mismo don Pedro, otro personaje, reconoce que por esa fama le conoce: «Ya te conozco / por el nombre, y he sabido / los aciertos de tu ciencia» ${ }^{21}$. El propio Carlino confiesa su filiación con el modelo literario:
Aunque sigo su modelo, no soy el Carlino, no, que honró el gaditano suelo, cuyos hechos escribió Góngora, que esté en el cielo.
En Cádiz fui su criado y dél aprendí tan bien lo embustero y lo avisado, que dirán los que me ven que soy el mismo mismado. Luego que el pobre murió,

\footnotetext{
19 Sepúlveda, 2003, p. 818.

${ }^{20}$ Dolfi, 1989, p. 499 y Góngora, El doctor Carlino, p. 20.

${ }^{21}$ Solís, El doctor Carlino, p. 492.
} 
nombre y grados le quité

vistiéndome dellos yo

y de Cádiz me ausenté

porque Madrid me llamó ${ }^{22}$.

Este metapersonaje que enarbola su capacidad de embuste - «del enredo y del embuste / soy en Madrid el yo autem» ${ }^{23}$ — finge su identidad, del mismo modo que don Diego huye de la corte a las Indias por una "pequeña travesura» y llega a Sevilla, donde adopta el nombre del otro galán, don Lope de Velasco, para así poder conquistar a doña Clara de Pacheco (prima de Lope), o de la misma forma que las dos damas, Leonor y Clara, que truecan sus nombres siguiendo las pautas del engaño ideado por Carlino. Al falso doctor le acompaña su mujer Casilda, cuyas intervenciones, según Carlino, la presentan como «simplísima criatura» ${ }^{24}$.

También significativos de esta ruptura de la verosimilitud dramática que, mediante alusiones literaturizadas, apuntan hacia lo cómico son una serie de apartes que Carlino, sin duda el protagonista de la comedia, dirige al público en la primera y en la segunda jornada. El primero de ellos encabeza la «relación puntual» de sus mañas; en dicho parlamento, el falso doctor se presenta ante el público y busca su complicidad confesando sus verdaderas intenciones, para compartir con el auditorio un espacio y tiempo de connivencia:

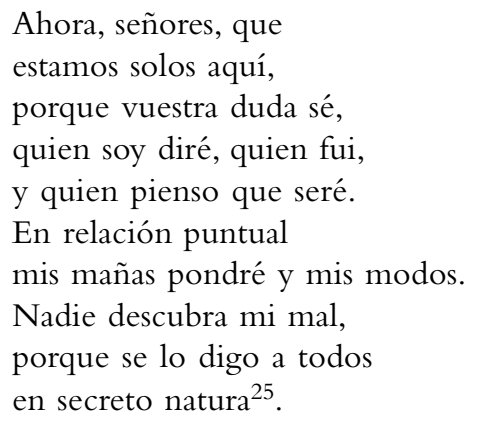

22 Solís, El doctor Carlino, p. 477.

23 Solís, El doctor Carlino, p. 476.

24 Solís, El doctor Carlino, p. 478.

25 Solís, El doctor Carlino, pp. 476-477. 
El siguiente aparte se da cuando sale a escena su esposa Casilda y Carlino apostilla continuamente sus intervenciones, en busca de la benevolencia del público por la simpleza de ella: «Ténganla ustedes en cuenta» y "¿No se lo dije yo a ustedes? / Siempre por la boca está / echando perlas» ${ }^{26}$. Más adelante Carlino también señalará al público cómo el enredo va embrollándose sin remedio, una vez que se ha presentado como el "yo autem del enredo», y debe acabar admitiendo que: «Esta es otra, / señores, a mí me empalan; / tomo coroza y no birlo» ${ }^{27}$.

Este protagonismo de Carlino, que se apunta ya en el título, y cuyo poder embaucador estaría ya en el horizonte de expectativas del público, condiciona, sin duda, el tratamiento del espacio y el tiempo en la comedia, otras dos convenciones genéricas básicas a la hora de trazar la evolución de la comedia de capa y espada. Su capacidad para el embuste se sirve de esa falsa profesión que le permite entrar y salir de las casas sin levantar sospechas, y su fama, aprendida del mismo Carlino de Góngora al que suplanta, se acrecienta en tanto que se cree capaz de resolver con engaños los lances que van produciéndose en un intervalo de tiempo tan reducido. Todo ello aderezado en una especie de vorágine de inverosímiles casualidades que suceden en un corto espacio de tiempo, alternando escenas de interior y urbanas.

La primera jornada transcurre en una noche y termina con las dos damas alojadas, en cuartos separados, en casa de Carlino. La segunda jornada empieza pronto en la mañana siguiente, antes de las diez, y hasta en dieciséis ocasiones hace referencia a todas las peripecias acaecidas durante la pasada noche (en la tercera jornada se seguirá recordando en varias ocasiones esa "noche anterior»). La tercera jornada continúa en el primer día y terminará al anochecer. Si los primeros versos del segundo acto presentaban al doctor Carlino con su agenda de embustes para el día y dejaban explícitamente acotado el inicio antes de las «diez en punto» de la mañana ${ }^{28}$, la tercera jornada introduce el dato del recuento de esa ronda de engaños y apunta que tan sólo ha transcurrido media hora:

26 Solís, El doctor Carlino, p. 478.

27 Solís, El doctor Carlino, p. 483.

28 Solís, El doctor Carlino, p. 487. 
DOCTOR Pero vamos a mis yerros; de casa habrá que salí media hora.

CASILDA Ya te vi, que te fuiste dado a perros, luego que llevó a Leonor su hermano, y a doña Clara su tío ${ }^{29}$.

A medida que va complicándose el caso, son varios los personajes que confirman que está atardeciendo con versos como «que la noche que ya empieza / dilate su negro manto» ${ }^{30}$. Así pues, resulta claro que la concentración temporal favorece una rápida sucesión de lances en un marco reducido a una sola noche y al día siguiente. Esta densidad de acontecimientos tiene mucho que ver con la incapacidad de Carlino para gestionarlos, y de ahí el efecto cómico, ya que el falso doctor se autoproclamaba antes «alcahuete de fama» por su repertorio de cautelas. La «relación puntual» de sus méritos ${ }^{31}$, que confesaba en aparte al público como "secreto natural» y a sus propios ojos le legitimaba para apropiarse de la identidad del Carlino gongorino, de quien aprendió tan bien lo embustero, no concuerda con lo que va sucediendo en escena.Y en ese desajuste entre los méritos que se atribuye el propio Carlino y el desarrollo dramático de sus embustes tienen mucho que ver las continuas interferencias dentro de su propia casa de Casilda y, esporádicamente, de don Pedro, cuando se dan en el exterior urbano.

Veamos primero lo que sucede en el espacio casero. Carlino facilitó los amores entre Lope y Leonor, y a raíz de su «falsedad tan afeitada» ${ }^{32}$ convenció a Diego, Lope y Leonor, para que buscaran amparo en su casa. Todos lo hicieron, curiosamente, apelando a su prudencia $^{33}$, lo cual demuestra cómo todos los personajes confiaron en él para llevar a cabo sus planes — menos el público que, gracias a los primeros apartes del falso doctor, ya conocía sus verdaderas inten-

29 Solís, El doctor Carlino, p. 511.

30 Solís, El doctor Carlino, p. 515.

31 Solís, El doctor Carlino, pp. 477-478.

32 Solís, El doctor Carlino, p. 477.

33 Solís, El doctor Carlino, pp. 475, 480 y 481. 
ciones. Carlino, confiado, pretendía así ejercer de alcahuete con dos parejas alojadas simultáneamente en su propia casa y en cuartos diferentes, y con el riesgo añadido de que uno de los caballeros era hermano de una de las damas. Pero la presencia de Casilda, a quien con sus apartes al público Carlino señaló como simple e incapaz, fue desbaratando el plan trazado por el falso doctor. Sobre el papel, el enredo urdido por Carlino tenía todas las de ganar, tal y como se lo explicaba a Casilda:

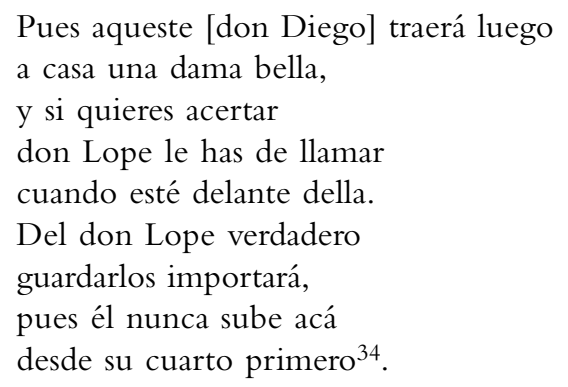

La distribución de una casa particular en el siglo XVII, como ya puso de manifiesto Antonucci ${ }^{35}$, favorecía y hacía verosímil el plan inicial de que las dos parejas de amantes nunca llegaran a encontrarse en la misma casa. Se cumplía así uno de los rasgos característicos de la comedia de capa y espada en la generación de Calderón, el aprovechamiento de los interiores, aunque Carlino no contaba con otra de las convenciones básicas del género: las llegadas imprevistas de los protagonistas. Estas apariciones inesperadas confunden a Casilda que, aunque sigue estrictamente las instrucciones de Carlino, termina en realidad dirigiéndose a cada uno según su verdadera identidad, en lugar de la fingida, tal como le había encomendado su esposo. Así ocurre, por ejemplo, en la segunda jornada, cuando don Pedro acude a casa de Carlino:

Pedro El padre del huésped soy que llegó anoche a esta casa por cierto acaso, y halló

${ }^{34}$ Solís, El doctor Carlino, p. 479.

35 Antonucci, 2002, pp. 57-58. 
tan buena acogida en ella como me ha dicho el doctor.

CASILDA (Ap. Éste es el padre de don Diego. ¿Qué diré? ¡Válgame Dios!

Mas si el doctor se lo ha dicho, ¿para qué me aflijo yo?)

Seáis, señor, bienvenido y pues bienvenido sois, decidme a lo que venís ${ }^{36}$.

Casilda duda, pero como don Pedro ha hablado con el doctor, termina presentándole a Clara como su sobrina, en lugar de introducirle a la fingida, es decir, a Leonor. Y si dentro del espacio doméstico es Casilda quien desbarata los planes de engaño, en el exterior urbano esa función recae en el padre de Lope, don Pedro. En ese juego de inverosímiles casualidades, en la tercera jornada, Diego descubre a Clara paseando en coche con su tío don Pedro, al que entonces pasa a considerar un rival amoroso. Diego va a devolver a su hermana Leonor a la casa familiar, pero en realidad están dando vueltas alrededor de la calle Mayor, siguiendo al coche en el que ha visto a su dama con un pretendiente. Así que, celoso, pretende descubrir la identidad del "caballero anciano» ${ }^{37}$, mientras que Leonor está convencida de que su hermano va a matarla de un momento a otro porque ha descubierto su galanteo con Lope. La sucesión de apartes de los hermanos, entre los celos del uno y la angustia de la otra, culmina con una confesión a medias de Leonor que, ahogándose literalmente de miedo, se desmaya cuando pasan, casualmente, enfrente de casa de don Pedro ${ }^{38}$. $\mathrm{Su}$ desvanecimiento hace que aparezca don Pedro con un criado para ofrecer su casa como amparo a la dama y propicia la posterior llamada al doctor Carlino.

Las dos mediaciones son significativas, en tanto que Casilda desempeña su papel en el interior doméstico y don Pedro en el exterior urbano. Ambos asumen las funciones que, por convención, se reservan a damas y varones, aunque, dentro del ambiente cómico generalizado que impone el protagonismo de Carlino, sus intervenciones

\footnotetext{
36 Solís, El doctor Carlino, p. 498.

37 Solís, El doctor Carlino, p. 515.

38 Solís, El doctor Carlino, p. 517.
} 
tendrán un marcado acento ridículo. Así, a Casilda se le reserva el protagonismo de interiores en una clara degradación, pues, según las pautas de la comedia de capa y espada, «es la dama quien abre y cierra los escotillones que dan acceso a este tablado interior ${ }^{39}$. En lo que atañe a don Pedro, que encarna el papel de guardián del honor, se le reserva para las escenas de exterior, aunque finalmente sea, precisamente, su casa el lugar donde Carlino tenga que terminar confesando la verdad del caso y, con ello, asumir su frustración (aunque todo sea un enredo):

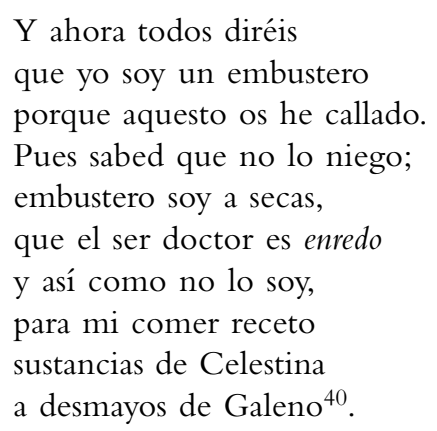

Para concluir, cabe decir que Solís sigue las pautas que, por los mismos años, Calderón tantea en comedias como El escondido y la tapa$d a$, caracterizadas por la búsqueda de nuevas vías creativas con las que sorprender a un público conocedor de todos los mecanismos del género. Por ello, El doctor Carlino también representa en 1635 un intento de Solís por manejar los mecanismos del enredo insistiendo en nuevas fórmulas autoreferenciales que, orientadas fundamentalmente hacia la comicidad, representan un nuevo ensayo por buscar la complicidad del público en una clara muestra de ingenio y oficio.

${ }^{39}$ Arata, 2002, p. 105.

${ }^{40}$ Solís, El doctor Carlino, p. 527. 


\section{BiBLIOGRAFÍA}

Antonucci, F., «El espacio doméstico y su representación en algunas comedias calderonianas de capa y espada", en Homenaje a Frédéric Serralta. El espacio y sus representaciones en el teatro español del Siglo de Oro, ed. F. Cazal, C. González y M. Vitse, Madrid / Frankfurt, Iberoamericana / Vervuert, 2002, pp. 57-81.

Arata, S., "Casa de muñecas: el descubrimiento de los interiores y la comedia urbana en la época de Lope de Vega», en Homenaje a Frédéric Serralta. El espacio y sus representaciones en el teatro español del Siglo de Oro, ed. F. Cazal, C. González y M. Vitse, Madrid / Frankfurt, Iberoamericana / Vervuert, 2002, pp. 91-115.

Arellano, I., "Convenciones y rasgos genéricos en la comedia de capa y espada», en La comedia de capa y espada, Madrid, Ministerio de Cultura, 1988, pp. 27-49 (Cuadernos de Teatro Clásico, 1).

- «La generalización del agente cómico en la comedia de capa y espada», Criticón, 60, 1994, pp. 103-128.

Arocena, L. A., Antonio de Solís, cronista indiano: Estudio sobre las formas historiográficas del barroco, Buenos Aires, Universidad de Buenos Aires, 1963.

Calderón de la Barca, P., Mañanas de abril y mayo. A. De Solís, El amor al uso, ed. I. Arellano y F. Serralta, Toulouse / Pamplona, Presses Universitaires du Mirail /Eunsa, 1995 (Anejos de Criticón, 5).

Checa Beltrán, J., «Bances Candamo, Luzán y el neoclasicimo», Edad de Oro, 31, 2012, pp. 111-127.

Cid, J. A., «Historia, Razón de Estado y burocracia. Antonio de Solís contra Jerónimo de Mascareñas (1662-1663)», Nueva Revista de Filología Hispánica, 47, 1991, pp. 73-97.

Dolfi, L., "Góngora y El Doctor Carlino de Antonio de Solís», Diálogos Hispánicos de Amsterdam, 8.2, 1989, pp. 481-502.

Ferrer Valls, T. (dir.), Diccionario biográfico de actores del teatro clásico español (DICAT), Kassel, Reichenberger, 2008.

Góngora, L. de, Teatro completo, ed. L. Dolfi, Madrid, Cátedra, 1993.

Granja, A. de la, «"Este paso ya está hecho". Calderón contra los mosqueteros», Anthropos. Extraordinarios, 1, 1997, pp. 73-84.

Julio, T., "La ocultación en la comedia de enredo de Rojas Zorrilla», en La comedia de enredo. Actas de las XX Jornadas de teatro clásico (1997), ed. F. B. Pedraza Jiménez y R. González Cañal, Almagro, Universidad de CastillaLa Mancha / Festival de Almagro, 1998, pp. 237-253.

Profeti, M. G., «El último Lope», en La década de oro de la comedia española (1630-1640), ed. F. Pedraza y R. González Cañal, Almagro, Universidad de Castilla-La Mancha / Festival de Almagro, 1997, pp. 11-39. 
Sepúlveda, J., «Haz y envés de convenciones en El escondido y la tapada de Pedro Calderón de la Barca», Criticón, 87-88-89, 2003, pp. 815-826.

Serralta, F., "Nueva biografía de Antonio de Solís y Rivadeneyra», Criticón, 33, 1986, pp. 51-157.

— «También hay duelo en las damas: Calderón y Solís», Criticón, 38, 1987, pp. 101-111.

Solís, A. de, El doctor Carlino, en Comedias de Antonio de Solís, ed. M. Sánchez Regueira, Madrid, CSIC, 1984, vol. 2, pp. 465-528. 